\title{
CORPORATE CITIZENSHIP GLOSSARY
}

B Corp Benefit Corporation: A title granted to companies that have been certified to meet rigorous standards of social and environmental performance, and have bylaws that take into account their impact on the environment, community, and employees.

B Lab: A nonprofit organization that offers certification to businesses to become "benefit corporations" which meet higher standards of corporate purpose, accountability, and transparency.

BoP Base/Bottom of Pyramid: a term referring to the number of people at the base of the global economic pyramid (4 billion), whose incomes are below $\$ 3000$ in local purchasing power.

CDP Carbon Disclosure Project: an international, notfor-profit organization offering a worldwide system for companies and cities to measure, disclose, manage, and share vital environmental information.

CFP Corporate Financial Performance: a term referring to a company's overall financial health and ability to generate revenue. 
CGI Clinton Global Initiative: founded by former President Bill Clinton, this organization brings together global leaders to create and implement innovative solutions to the world's most pressing challenges.

CO2e Carbon Dioxide Equivalent: a measure used to compare the emissions from greenhouse gases based upon their global warming potential.

CSP Corporate Social Performance: often used as a synonym for corporate social responsibility (CSR). CSP refers to a company's interaction with the community on economic, environmental, and social issues.

CSR Corporate Social Responsibility: efforts by businesses to work with stakeholders to achieve improved economic, environmental, and social performance, sometimes known as the triple bottom line and also identified as corporate citizenship or sustainability.

CVC Corporate Volunteer Council: local networks for companies to share effective practices and address community needs through workplace volunteering, many of which are affiliated with local community-based agencies (HandsOn Network, Volunteer Centers, and United Way).

DJSI Dow Jones Sustainability Index: a family of indices managed by RobecoSam Indices and S\&P Dow Jones that track the stock performance of companies according to economic, environmental, and social criteria, offering a measurement by which investors can judge the sustainability impact of their investment choices. 
EHS Environmental, Health and Safety: a traditional name for departments in organizations responsible for implementing and managing environmental and occupational health and safety programs.

EICC Electronic Industry Citizenship Coalition: a partnership of the world's leading electronics companies working to improve efficiency and social, ethical, and environmental responsibility in the global supply chain.

EMS Environmental Management System: a framework that assists companies in establishing control over operations in order to lessen their environmental impacts and increase overall efficiency.

ESG Environmental, Social, and Governance: a general term used to describe the three primary areas of import for companies focused on making their operations sustainable. These three performance dimensions are often highlighted and evaluated by companies in their sustainability reports.

EVP Employee Volunteer Program: a type of program that aims to engage employees while helping the local community.

FASB Financial Accounting Standards Board: a private, not-for-profit organization that develops the financial accounting standards for the private sector in the United States.

FSC Forest Stewardship Council: an independent, nonprofit membership organization that protects forests by 
setting standards for responsible forest management under which forests and companies are certified.

GAAP Generally Accepted Accounting Principles: a set of concepts developed by the Financial Accounting Standards Board that determine how organizations in the United States prepare, present, and report their financial statements.

GASB Governmental Accounting Standards Board: an independent organization that establishes and improves standards of accounting and financial reporting for US state and local governments.

GHG Greenhouse Gases: gases that trap heat in the atmosphere causing the greenhouse effect that supports life on earth, but that can have dangerous effects if their concentrations increase too much.

GHG Protocol Greenhouse Gas Protocol: an international accounting tool for businesses and governmental organizations to track, calculate, and manage their greenhouse gas emissions. The protocol almost always serves as the benchmark for other greenhouse gas standards developed throughout the world.

GIIN Global Impact Investing Network: a nonprofit organization that works to increase the scale and effectiveness of impact investments, which are investments made in companies, organizations, and funds with the purpose of creating positive social and environmental impact in addition to financial return. 
GIIRS Global Impact Investing Ratings System: a ratings system that measures the social and environmental impact of companies and funds. GIIRS likens its assessment system to that of Morningstar investment rankings and Capital IQ financial analytics.

GISR Global Initiative for Sustainability Ratings: an initiative whose mission is to design a generally accepted ratings framework for assessing the sustainability performance of companies.

GRI Global Reporting Initiative: a nonprofit organization that works toward a sustainable global economy by providing sustainability reporting assistance, specifically their widely known Sustainability Reporting Framework.

GSA General Services Administration: a federal agency that provides and maintains buildings, acquires goods and services, and promotes administrative best practices and efficient operations for the US government.

HIP Human Impact and Profit: a measurement and management tool that quantifies the products, services, operations, and management practices of sustainability and citizenship and is used both by corporations and investors.

IIRC International Integrated Reporting Council: an international coalition of regulators, investors, companies, standard setters, accounting professionals, and NGOs that seeks to create the most commonly used framework for corporate reporting. Their "integrated report" method encourages companies to consider all 
aspects of an organization in reporting (strategy, governance, performance, and prospects) to increase their value creation over the short, medium, and long term.

ISO International Organization for Standardization: a Swiss-based organization that brings together representatives from around the world to agree on voluntary international standards for products, services, and good practice, seeking to make businesses more effective and efficient.

IRIS Impact Reporting and Investment Standards: established by the Global Impact Investing Network (see GIIN), these performance standards are used by impact investors to determine and evaluate the social, environmental, and financial success of impact investments and the impact investment industry at large.

IVA Intangible Value Assessment: a tool that assesses companies' financially material risks and opportunities arising from environmental, social, and governance factors.

KPI Key Performance Indicators: areas of measurement by which companies can track their performance in relation to their business objectives, often utilizing target goals or ranges as benchmarks for future evaluation.

L3C Low-profit Limited Liability Company: a company focusing principally on charitable or educational goals that may make a small profit, as long as making a profit is not the primary purpose of the organization. L3Cs are 
often considered hybrid organizations between nonprofit and profit entities.

LCA Life Cycle Assessment: a measurement of the potential environmental aspects and impacts of any organization, product, or service. This assessment evaluates every stage of development, allowing for a "cradle to grave" estimation of environmental effects.

MDGs Millennium Development Goals: eight objectives officially established by the United Nations in 2000, from the eradication of extreme poverty, to the advancement of environmental sustainability, to halting the spread of HIV/AIDs; all to be met by a target date of 2015 .

NCA Natural Capital Accounting: a type of accounting that measures the indispensable resources and benefits essential for human survival and economic activity provided by the ecosystem. Natural capital is commonly divided into renewable resources (agricultural crops, vegetation, and wildlife) and nonrenewable resources (fossil fuels and mineral deposits).

NGO Non-Governmental Organization: a not-for-profit group, principally independent from government, which is organized on a local, national, or international level to address issues in support of the public good.

OECD Organization for Economic Cooperation and Development: a global organization of representatives from 34 member countries that meets to advance ideas and review progress in specific policy areas, such as 
economics, trade, science, employment, education, and financial markets.

PRI Principles for Responsible Investment: the six principles of responsible investing supported by institutional investors who believe that environmental, social, and corporate governance issues can affect the performance of investment portfolios.

SASB Sustainability Accounting Standards Board: a nonprofit organization engaged in the development and dissemination of industry-specific sustainability accounting standards in the United States.

SDGs Sustainable Development Goals: The successor initiative to the Millennium Development Goals (MDGs) of the United Nations. The SDGs, officially known as Transforming our world: the 2030 Agenda for Sustainable Development is a set of seventeen aspirational "Global Goals" with 169 targets between them intended to eliminate poverty and reverse climate change.

SRI Socially Responsible Investing: values-based asset portfolio management.

SROI Social Return on Investment: a method to quantify and monetize the social value created by an organization's programs, especially those in the nonprofit sector. This process was created by an American company, REDF, in the 1990 s and is widely used today.

SSRN Social Science Research Network: an organization devoted to the worldwide distribution of social science 
research, comprised of a number of specialized networks in each of the social sciences.

TBL Triple Bottom Line: a term, created by Sustainability founder John Elkington in the 1990s, encapsulating three particular assessment areas by which businesses and investors should measure value: economic, social, and environmental.

UNGC United Nations Global Compact: a global initiative established in 2000 that provides a principle-based framework for businesses to adopt more sustainable and socially responsible policies in the areas of human rights, labor standards, anticorruption, and the environment.

UNPRI United Nations Principles of Responsible Investing: a United Nations supported initiative convening investors to put the six principles of responsible investing into practice through investment decisionmaking and ownership practices. 